\title{
Comparing Alternative Breast Milk Feeding Questions to U.S. Breastfeeding Surveillance Questions
}

\author{
Elizabeth O'Sullivan \\ Technological University Dublin, Ireland, liz.osullivan@tudublin.ie \\ Sheela R. Geraghty \\ University of Cincinnati \\ Patricia Cassano \\ Cornell University
}

See next page for additional authors

Follow this and additional works at: https://arrow.tudublin.ie/scschbioart

Part of the Dietetics and Clinical Nutrition Commons, and the Maternal, Child Health and Neonatal Nursing Commons

\section{Recommended Citation}

Elizabeth J. O'Sullivan, Sheela R. Geraghty, Patricia A. Cassano, and Kathleen M.

Rasmussen.Breastfeeding Medicine.Jun 2019.347-353.http://doi.org/10.1089/bfm.2018.0256

This Article is brought to you for free and open access by the School of Biological Sciences at ARROW@TU Dublin. It has been accepted for inclusion in Articles by an authorized administrator of ARROW@TU Dublin. For more information, please contact arrow.admin@tudublin.ie, aisling.coyne@tudublin.ie,gerard.connolly@tudublin.ie. Funder: The Academy of Nutrition and Dietetics Foundation

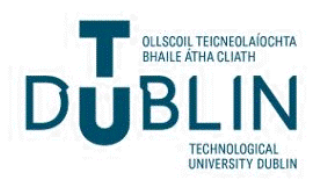


Authors

Elizabeth O'Sullivan, Sheela R. Geraghty, Patricia Cassano, and Kathleen M. Rasmussen

This article is available at ARROW@TU Dublin: https://arrow.tudublin.ie/scschbioart/302 


\title{
Comparing Alternative Breast Milk Feeding Questions to U.S. Breastfeeding Surveillance Questions
}

\author{
Elizabeth J. O'Sullivan, ${ }^{1,2}$ Sheela R. Geraghty, ${ }^{3}$ Patricia A. Cassano, ${ }^{1}$ and Kathleen M. Rasmussen ${ }^{1}$
}

\begin{abstract}
Background: Most mothers in the United States express their milk, which is then bottle fed to their infants. The National Immunization Survey (NIS), used to report national breastfeeding prevalence, asks about infant breast milk consumption, regardless of whether it is consumed at the mother's breast or from a bottle. The NIS data are often erroneously interpreted, however, to mean prevalence of at-the-breast feeding. We hypothesized that over half of infants classified as breastfed at 3,6, and 12 months by the NIS questions would also be consuming expressed breast milk.

Materials and Methods: A convenience sample of 456 mothers of infants 19-35 months of age recruited through ResearchMatch.org completed an online infant-feeding questionnaire. The questionnaire included both the NIS questions and more-detailed questions about feeding mode, distinguishing between at-the-breast and bottle.

Results: Based on responses of our sample to the NIS questions, it could be interpreted that $74 \%, 64 \%$, and $39 \%$ of mother-infant dyads were at-the-breast feeding at 3, 6, and 12 months, respectively. However, at each time point, most infants consumed at least some breast milk from a bottle. As infants got older, the proportion of breast milk consumed from a bottle increased.

Conclusions: In this U.S. sample, the predominant breast milk feeding style involves both at-the-breast and expressed breast milk feeding. Future research and national surveillance should consider including separate measures of maternal breast milk expression and infant consumption of expressed breast milk to enable meaningful exploration of maternal and infant outcomes associated with these asynchronous behaviors.
\end{abstract}

Keywords: breast milk expression, expressed breast milk feeding, epidemiology, surveillance

\section{Introduction}

I $\mathrm{T}$ IS WELL ESTABLISHED that infant formula is associated with worse infant outcomes ${ }^{1-3}$ than breastfeeding as traditionally defined, namely an infant suckling milk from his or her mother's breast. Studies have shown beneficial outcomes for infants fed directly at their mothers' breast versus infants fed formula from a bottle. ${ }^{4-11}$ Thus, health organizations worldwide promote what has been considered to be "breastfeeding.", 12,13 However, with the wide availability of efficient electric breast pumps, and the high proportion of mothers working outside the home, ${ }^{14}$ a significant proportion of mothers now express their breast milk, which is then fed from a bottle. ${ }^{15,16}$ Thus, the dichotomous classification of infants as breastfed or bottle-fed, with bottle-fed signifying the feeding of infant formula, is no longer completely accu- rate, and the meaning of the word breastfeeding has become unclear. ${ }^{17-20}$

The national breastfeeding surveillance tool in the United States, the National Immunization Survey (NIS), has been used to monitor and report breastfeeding prevalence since $2001 .^{21}$ However, the NIS questions ask only about infant breast milk consumption, regardless of whether breast milk was consumed at the mother's breast or from a bottle. Given that the NIS questions ask how long an infant was "breastfed or fed breast milk," this could be taken to mean a combination of at-the-breast feeding and expressed breast milk feeding. However, the NIS data are often interpreted, erroneously, to mean the prevalence of at-the-breast feeding. ${ }^{12,22}$ This is problematic because maternal breast milk production and infant breast milk consumption are no longer synchronous behaviors. ${ }^{19}$

\footnotetext{
${ }^{1}$ Division of Nutritional Sciences, Cornell University, Ithaca, New York.

${ }^{2}$ School of Biological and Health Sciences, Technological University Dublin, Dublin, Ireland.

${ }^{3}$ Cincinnati Children's Center for Breastfeeding Medicine, University of Cincinnati College of Medicine, Cincinnati, Ohio.
} 
It is important to understand and recognize the complexity of breast milk feeding practices because recently published data associated infant expressed breast milk consumption with higher infant growth velocity during the first year of life, ${ }^{5,6,11}$ higher risk of wheezing and coughing, ${ }^{7}$ increased risk of otitis media, ${ }^{9}$ lower satiety responsiveness in children, ${ }^{4}$ and less desirable children's eating behavior at 6 years of age ${ }^{8}$ when compared with feeding directly at the breast. It is possible that other outcomes differ by infant breast milk consumption mode, but that they remain to be studied. Given that $85 \%$ of mothers of infants 1.5 to 4.5 months of age who responded to the Infant Feeding Practices Study II (IFPS II, 2005-2007) ${ }^{23}$ reported that they had expressed their milk at some time and $25 \%$ reported doing so on a regular schedule, the infant health outcomes associated with these feeding behaviors warrant further study.

Our primary aim in this research was to compare alternative infant-feeding questions, which include indicators for maternal breast milk expression and infant expressed breast milk consumption, with the current NIS questions-which do not elicit data about maternal breast milk expression or infant breast milk consumption-to determine whether the prevalence of feeding behaviors differs depending on the questions asked. Based on the prevalence of maternal breast milk expression observed on the IFPS II $^{23}$ we hypothesized that most mothers in our sample would have expressed their milk at some time and more than $50 \%$ of infants who were classified as breastfeeding at 3,6, and 12 months by the NIS questions would have been consuming breast milk both at the breast and from a bottle. We also aimed to explore the discordance between the duration of maternal breast milk production and infant breast milk consumption, and the timing of cessation of infant formula consumption.

\section{Materials and Methods}

\section{Data collection}

We conducted a cross-sectional, online questionnaire that included the NIS questions, an alternative set of infant-feeding questions (the Questionnaire on Infant Feeding [QIF]), and demographic questions. The QIF (Supplementary Table S1) asked about the timing of initiation and cessation of several behaviors: at-the-breast feeding, maternal breast milk expression, infant expressed breast milk consumption, infant formula consumption, the timing of introduction of foods or liquids other than breast milk or infant formula, instances of breast milk sharing, and the frequency of maternal breast milk expression. A description of the development, construct validity testing, and reliability testing of the QIF has been published elsewhere. ${ }^{24}$ Participants could respond in days, weeks, months, or a combination of these; we recoded responses into days for analyses. We also asked categorical, closed questions about the mode of feeding (breast/bottle) at 3,6 , and 12 months postpartum and the proportion of breast milk infants consumed from a bottle. The QIF included a prompt encouraging mothers to think carefully and respond as accurately as possible.

We recruited participants through ResearchMatch, a U.S. national health volunteer registry supported by the National Institutes of Health as part of the Clinical Translational Science Award program. ${ }^{25}$ Between March and July 2015, we contacted all women in the registry between 18 and 50 years of age with a message that invited mothers of children 19-35 months of age to complete a questionnaire about infant and child feeding. The child's age range was chosen to mimic the sampling strategy of the NIS. Those interested clicked a link in the e-mail, which gave ResearchMatch permission to release their contact details to the investigators. We then e-mailed mothers a personalized link to the questionnaire. The first page of the questionnaire explained the purpose of the study; respondents were informed that participation was voluntary and confidential and asked for their agreement to participate. Respondents clicked a button labeled "I AGREE" to begin the questionnaire. Respondents were considered to have consented to participate when they began to complete the questionnaire. All mothers were eligible to participate, whether they ever fed breast milk or not. The questionnaire was only offered in English. We compensated participants with a $\$ 5$ electronic gift card, e-mailed to them within 24 hours of questionnaire completion. This protocol was approved by the Cornell University's Institutional Review Board.

\section{Data cleaning}

We modified or removed implausible and logically impossible responses to questions about maternal and infant behaviors and demographic characteristics during data cleaning. In some cases, implausible responses $(n=10)$ appeared to be typographical errors; we manually altered these to the more plausible response. For example, one participant responded "no" to the NIS question "Was [child] breastfed or fed breast milk?"' but all other responses - to both the NIS questions and the QIF questions - indicated that the child was fed breast milk, so this response was modified to "yes." In cases where there was no obvious correct response (13 responses to individual questions), we set values to missing. We excluded participants with internally inconsistent responses. Internally inconsistent responses included participants who indicated that they stopped a behavior (e.g., expressing breast milk) before they started it $(n=20)$, participants who reported continuing a feeding behavior for longer than their child had been alive $(n=4)$, and participants whose responses were inconsistent across the two feeding questionnaires (NIS and QIF; $n=4$ ).

\section{Variable creation}

With the NIS questions, we used continuous responses to create dichotomous variables indicating whether the infant was "breastfed or being fed breast milk" at 3, 6, and 12 months. For example, if a mother responded to the question "How old was [child's name] when [child's name] completely stopped breastfeeding or being fed breast milk?" with "7 months," then the infant was coded as "breastfed or being fed breast milk" at 3 and 6 months, but not at 12 months. Similarly, we used continuous responses to the QIF questions to create dichotomous variables indicating whether the mother-infant dyad was at-the-breast feeding, whether the mother was expressing breast milk, and whether the infant was consuming expressed breast milk at 3, 6, and 12 months. For example, the two questions "If day 0 is the day [child] was born, how old was he/she when he/she was first fed directly from your breast?" and "Thinking only about feeding directly from your breast, if day 0 is the day [child] 
was born, how old was he/she when he/she completely stopped feeding directly from your breast?' (QIF questions available in the Supplementary Table S1) were used to determine whether a child was consuming milk at-the-breast at 3,6 , and 12 months.

\section{Data analyses}

First, we calculated the proportion of mothers who ever expressed breast milk. Second, we used the responses to the NIS questions to calculate the proportion of infants who were consuming any breast milk at 3, 6, and 12 months, and exclusively consuming breast milk at 3 and 6 months. We then compared these proportions with responses to the QIF questions that distinguish between at-the-breast consumption of breast milk and expressed breast milk consumption.

We explored the discordance between the duration of maternal breast milk production and infant breast milk consumption and the timing of cessation of infant formula consumption using descriptive statistics. All analyses were conducted using SAS version 9.3 software (SAS Institute, Inc., Cary, NC).

\section{Results}

Eight hundred ninety-three people expressed interest in this research and were e-mailed the questionnaire; the questionnaire was completed by 496 respondents (Fig. 1). Before conducting the present analyses, we assessed the construct validity and reliability of our questionnaire ${ }^{20}$ and reported that a small number of participants had incompatible responses across the two surveys; these participants $(n=8)$ were excluded from the present analyses. We also excluded participants who had questionable responses discovered during data cleaning $(n=28)$ and those who provided demographic information but did not complete infant-feeding questions $(n=4)$ from the final analyses. Thus, final analyses include 456 participants $(92 \%, 456 / 496)$.
Most respondents were white, non-Hispanic, 30 years of age or older, married, normal weight, had at least a bachelor's degree, and had children who did not participate in the Special Supplemental Nutrition Program for Women, Infants, and Children (WIC) (Table 1). Although we aimed to recruit mothers of infants between 19 and 35 months of age, some of the respondents had younger $(\sim 4 \%)$ and some had older $(\sim 13 \%)$ infants. Infants in the sample were born in 2011, 2012, and 2013.

\section{Maternal breast milk expression and infant breast milk consumption}

Of the breast milk feeding mothers surveyed, $94 \%$ ever expressed their milk, and the majority (51.5\%) of breast milk feeding mothers expressed several times every day. Most mothers ( $\sim 75 \%$ of the total sample) used a mixed-mode feeding style, including at-the-breast feeding and at least some expressed breast milk feeding (Fig. 2). Fewer than $10 \%$ of all mothers only ever fed breast milk solely at the breast (Fig. 2, Column 2). A small proportion of respondents reported that their infants only ever consumed expressed breast milk $(\sim 3 \%)$ and for a few of the respondents $(n=4)$, the only breast milk their child consumed was another mother's milk (Fig. 2). The NIS questions do not ask about maternal breast milk expression or infant breast milk consumption; as such, we cannot report the prevalence of these behaviors based on this questionnaire.

The proportion of infants consuming breast milk at 3,6 , and 12 months is roughly the same when measured by the NIS and the QIF (Fig. 3). However, using the additional data collected in the QIF, we can report that of the infants who consumed breast milk at 3, 6, and 12 months, most consumed both at the breast and expressed breast milk (Fig. 3), making a mixed-mode style the predominant feeding style across the infant's first year-confirming our hypothesis. Prevalence of exclusive breast milk consumption at 3 and 6 months was similar regardless of question type (NIS: $22.6 \%$ and $8.1 \%$, respectively, versus QIF: $19.5 \%$ and $6.1 \%$, respectively).
FIG. 1. Flowchart of participants in the questionnaire on infant feeding, 2015.

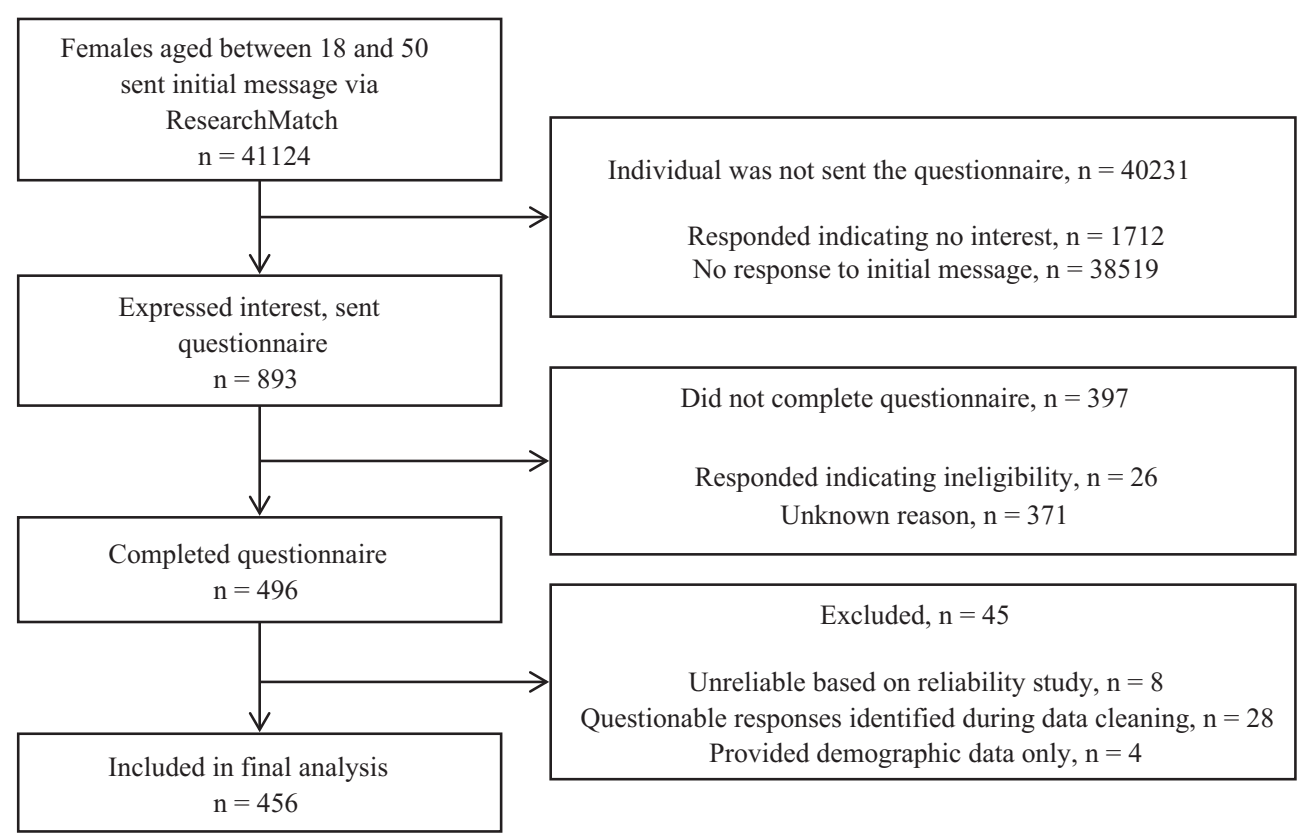


Table 1. Demographic Characteristics OF PARTICIPANTS IN THE QUESTIONNAIRE ON INFANT FEEDING 2015, Total $N=456$

\begin{tabular}{|c|c|}
\hline Characteristic & Number (\%) \\
\hline \multicolumn{2}{|l|}{ Maternal age, years } \\
\hline$<30$ & $127(27.9)$ \\
\hline$\geq 30$ & $329(72.1)$ \\
\hline \multicolumn{2}{|l|}{ Infant age, months ${ }^{\mathrm{a}}$} \\
\hline$<19$ & $19(4.2)$ \\
\hline $19-23$ & $107(23.4)$ \\
\hline $24-29$ & $154(33.8)$ \\
\hline $30-35$ & $118(25.9)$ \\
\hline$>35$ & $58(12.7)$ \\
\hline \multicolumn{2}{|l|}{ Maternal education $^{\mathrm{a}}$} \\
\hline Less than bachelor's degree & $139(30.5)$ \\
\hline Bachelor's degree or higher & $317(69.5)$ \\
\hline \multicolumn{2}{|l|}{ Maternal $\mathrm{BMI}^{\mathrm{a}}, \mathrm{kg} / \mathrm{m}^{2}$} \\
\hline$<18.5$ (underweight) & $15(3.3)$ \\
\hline $18.5-24.9$ (normal weight) & $193(42.3)$ \\
\hline 25-29.9 (overweight) & $131(28.7)$ \\
\hline$\geq 30$ (obese) & $117(25.7)$ \\
\hline \multicolumn{2}{|l|}{ Ethnicity } \\
\hline Hispanic/Latino & $28(6.1)$ \\
\hline Non-Hispanic & $428(93.9)$ \\
\hline \multicolumn{2}{|l|}{ Race } \\
\hline White & $386(84.7)$ \\
\hline Black or African American & $47(10.3)$ \\
\hline Other & $23(5)$ \\
\hline \multicolumn{2}{|l|}{ U.S. residence region ${ }^{\mathrm{a}}$} \\
\hline Northeast & $54(11.9)$ \\
\hline Midwest & $164(36.2)$ \\
\hline South & $166(36.7)$ \\
\hline West & $69(15.2)$ \\
\hline \multicolumn{2}{|l|}{ Returned to work postpartum } \\
\hline No & $78(17.3)$ \\
\hline Yes, part-time only & $92(20.5)$ \\
\hline Yes, full-time & $280(62.2)$ \\
\hline \multicolumn{2}{|l|}{ Marital status $^{\mathrm{a}}$} \\
\hline Married & $359(78.7)$ \\
\hline Not married & $97(21.3)$ \\
\hline \multicolumn{2}{|l|}{ Index child was adopted ${ }^{\mathrm{b}}$} \\
\hline No & $450(98.7)$ \\
\hline Yes & $6(1.3)$ \\
\hline \multicolumn{2}{|c|}{ Number of children mother has given birth to ${ }^{a}$} \\
\hline 1 & $197(44.7)$ \\
\hline$>1$ & $244(55.3)$ \\
\hline \multicolumn{2}{|l|}{ Infant ever participated in WIC } \\
\hline Yes & $117(25.7)$ \\
\hline No & $339(74.3)$ \\
\hline
\end{tabular}

${ }^{\mathrm{a}}$ At survey completion.

${ }^{\mathrm{b}}$ Based on participant-initiated self-report.

BMI, body mass index; WIC, the Special Supplemental Nutrition Program for Women, Infants, and Children.

Based on responses to a categorical question about the proportion of expressed breast milk consumed at different times throughout infancy, at 3 months postpartum, nearly $70 \%$ of breast milk feeding mothers reported that their infants consumed at least some breast milk from a bottle (Table 2). However, at-the-breast feeding was the predominant breast milk feeding mode at 3 months. At 6 and 12 months postpartum, the proportion of infants who consumed breast milk from a bottle increased, as did the proportion of breast milk they received from a bottle relative to at-the-breast (Table 2).

\section{Additional behaviors of public health interest}

Of the breast milk feeding mothers in this sample, 36 $(10.1 \%)$ continued to feed their infants expressed breast milk for at least 4 weeks after they stopped lactating. The median duration of infant breast milk consumption after cessation of maternal lactation - among those who continued to feed their infant expressed breast milk for at least 4 weeks after cessation of maternal lactation-was 57 (range 28-162) days. Of those women whose infants consumed expressed breast milk for at least 4 weeks after cessation of maternal lactation, 58\% $(n=21)$ provided answers to the NIS questions that reflected the shorter duration of maternal breast milk production and not the duration of infant breast milk consumption, which is the focus of the NIS questions. The remaining 42\% $(n=15)$ provided answers to the NIS questions that reflected duration of infant breast milk consumption.

The majority $(75 \%)$ of mothers reported that their infant ever consumed infant formula in response to the QIF. Of these, $5.2 \%$ of infants $(n=17)$ received infant formula for 3 days or less. Six of these mothers with a short duration of infant formula feeding reported that their infant never consumed infant formula in response to the NIS questions, but subsequently reported feeding infant formula on the moredetailed questionnaire.

\section{Discussion}

Our results indicate that a mixed-mode breast milk feeding style - combining both at-the-breast feeding and expressed breast milk feeding - is the predominant breast milk feeding style among a large sample of U.S. mothers. Given that a mixed-mode breast milk feeding style is the predominant feeding style, and that expressed breast milk feeding may not confer the same benefits as at-the-breast feeding, the health outcomes associated with this feeding mode warrant in-depth study.

At all times across infancy that we explored, the predominant breast milk feeding strategy included both at-thebreast feeding and expressed breast milk feeding. If the NIS questions are interpreted literally, as the duration a child was "breastfed or fed breast milk," then most infants in our sample would be correctly classified by the NIS as it stands now. However, the NIS questions do not accurately reflect the behavior of the mothers only feeding at the breast or the infants only consuming expressed breast milk. For example, based on responses of women in our sample to the NIS questions, it could be interpreted that $74 \%, 64 \%$, and $39 \%$ of all mother-infant dyads were breastfeeding at 3, 6, and 12 months, respectively. However, at 3, 6, and 12 months $14.4 \%, 11.4 \%$, and $14.5 \%$ of infants, respectively, were consuming breast milk solely at the breast and $7.5 \%, 7.7 \%$, and $3.1 \%$ of infants were consuming expressed breast milk only. The prevalence of exclusive expressed breast milk consumption observed among our sample is comparable with a recent report of a cross-sectional study from one geographic location. ${ }^{26}$ 


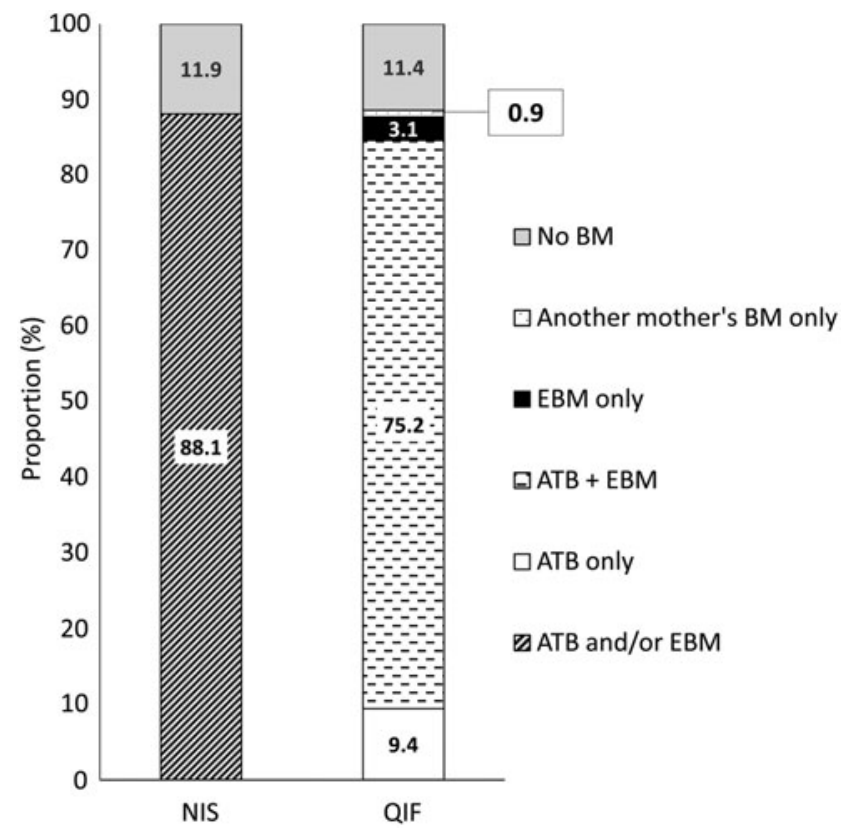

FIG. 2. Proportion of infants in the QIF (2015) ever fed breast milk by question type (NIS versus QIF), calculated using responses to questions about timing of initiation and cessation of feeding behaviors. ATB, at-the-breast; BM, breast milk; EBM, expressed breast milk; NIS, National Immunization on Survey; QIF, Questionnaire on Infant Feeding.

This less-extensive classification of maternal and infant behaviors by the NIS questions is important because public health authorities ${ }^{12}$ recommend that women breastfeed. This recommendation is based on associations of breastfeeding with positive maternal and infant outcomes ${ }^{2}$-associations based on studies comparing infants fed at the breast with those fed infant formula from a bottle. However, most mothers feed infants at the breast and express their milk, and thus most infants are fed breast milk both at the breast and from a bottle; the latter feeding style may modify the benefits of at-the-breast feeding and could even be associated with negative infant outcomes.

Our results not only describe the complexity of breast milk feeding, but also the complexity of measuring these behaviors. When dichotomous variables were created from responses to questions with continuous responses, $\sim 14 \%$ of dyads were classified as solely at-the-breast feeding at 3 months postpartum. In contrast, when asked a categorical question specifically about the proportion of breast milk fed at the breast, $\sim 30 \%$ of dyads were classified as solely at-thebreast feeding at 3 months postpartum. This difference likely occurs because expressed breast milk feeding may be an episodic behavior; for example, a mother may choose to express enough milk to spend a few nights away from her infant but may only feed at the breast when they are together. Thus, it is insufficient to ask only about the initiation and cessation of this behavior to describe, for example, the behavior of an infant who started consuming expressed breast milk before 3 months, stopped after 3 months, but was only fed at the breast at 3 months of age.

The difficulty in measuring breast milk production and consumption behaviors highlighted in this study is essential for investigators to consider when developing studies to explore maternal and infant outcomes related to maternal lactation and infant breast milk consumption. Take, for example, the association between breastfeeding and the development of the infant gut microbiome. Compared with formula feeding, breastfeeding is associated with development of a more favorable infant gut microbiome,$^{27,28}$ which itself is associated with reduced risk of metabolic and immune diseases. ${ }^{27}$ However, infants who consume expressed breast milk may
FIG. 3. Prevalence of breast milk feeding at 3, 6, and 12 months in the Questionnaire on Infant Feeding (2015) by question type (NIS versus QIF), calculated using responses to questions about timing of initiation and cessation of feeding behaviors.

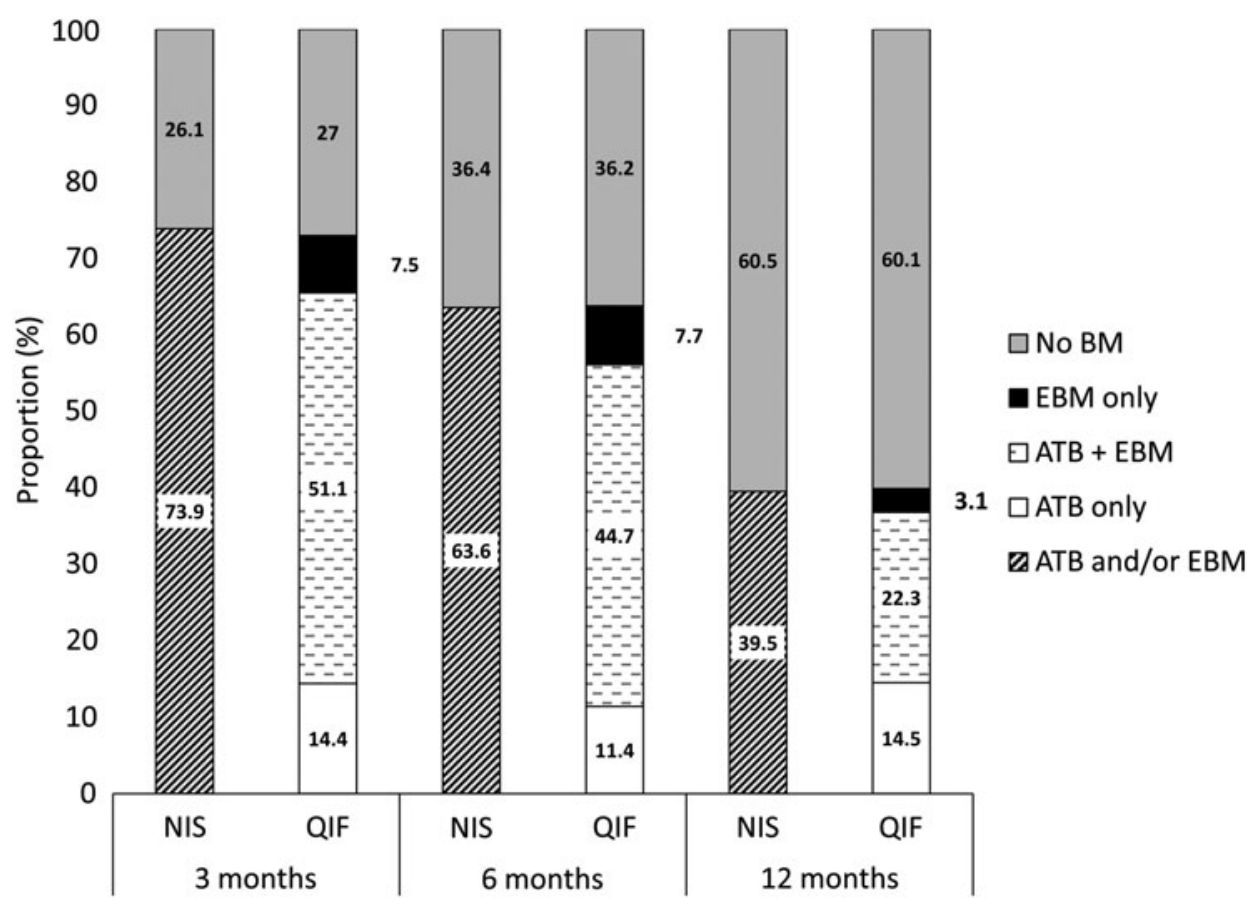


Table 2. Mode of Breast Milk Feeding in the First Year Postpartum Among Breast Milk Feeding PARTICIPANTS IN THE QUESTIONNAIRE ON INFANT FEEDING, 2015

\begin{tabular}{lccc}
\hline $\begin{array}{l}\text { Breast milk } \\
\text { feeding category }\end{array}$ & $\begin{array}{c}3 \text { months } \\
(\mathrm{n}=340)\end{array}$ & $\begin{array}{c}6 \text { months } \\
(\mathrm{n}=294)\end{array}$ & $\begin{array}{c}12 \text { months } \\
(\mathrm{n}=195)\end{array}$ \\
\hline ATB only & $104(30.6)$ & $43(14.6)$ & $42(21.6)$ \\
Mostly ATB, some EBM & $132(38.8)$ & $81(27.6)$ & $35(17.9)$ \\
Half ATB, half EBM & $49(14.4)$ & $98(33.3)$ & $48(24.6)$ \\
Some ATB, mostly EBM & $19(5.6)$ & $30(10.2)$ & $44(22.6)$ \\
EBM only & $36(10.6)$ & $42(14.3)$ & $26(13.3)$ \\
\hline
\end{tabular}

Values are percent of the total number of mothers who reported breast milk feeding on this question. See Supplementary Table S1 for full text of question from which these data are obtained.

"Participants were free to interpret the words "mostly" and "some" as they felt appropriate.

ATB, at-the-breast; EBM, expressed breast milk.

develop a gut microbiome than is less favorable than that of the infant who consume milk at the breast. This is because practices for storing and reheating expressed breast milk ${ }^{29}$ can decrease the $\mathrm{pH}$ and change the bacterial profile of the milk. ${ }^{30}$ Thus, the proportion of expressed breast milk consumed would be an important exposure to measure when exploring the complex relationships among infant feeding, the gut microbiome, and infant health outcomes.

The other feeding behaviors of public health interest that we explored, about which no national data are collected, suggest a possible need for revision of the current national breastfeeding surveillance questions. Based on formative qualitative data, ${ }^{19}$ we predicted that some infants would continue consuming breast milk after their mothers had stopped producing breast milk. Although this occurred, most mothers of infants who continued to consume expressed breast milk after their mother had stopped lactating provided answers to the NIS questions that reflected their own duration of lactation, which underestimates the infant's duration of breast milk consumption. This finding supports the need for more specific questions for measuring infant feeding.

In this study, when presented with questions about both the initiation and cessation of infant formula feeding, $6(1.3 \%)$ mothers who had previously indicated that their child never consumed infant formula provided information about formula feeding. This is important for two reasons. First, investigators may misclassify infants as never formula fed if they only ask about initiation of infant formula feeding. Second, when mothers in a study we previously conducted were not offered the opportunity to provide a timing of infant formula cessation, they were frustrated, ${ }^{21}$ which may be sufficient justification for collecting the data.

\section{Strengths and limitations}

A strength of this study is the development of the questionnaire based on formative qualitative research. ${ }^{19,31}$ Questions were rigorously tested to ensure they were contextually appropriate and reliable. Additionally, by administering the questionnaire online to a large sample from a wide geographic area, we verified the inferences we drew from our smaller qualitative study, conducted in a single geographic location. ${ }^{19,31}$ The similar conclusions drawn from these studies, particularly the finding that a mixed-mode breast milk feeding style is the predominant feeding style, supports the generalizability of these findings, despite the fact that we surveyed a convenience sample of women.

However, because we administered this questionnaire online to a convenience sample of mothers recruited through ResearchMatch.org, ${ }^{25}$ we have no proof that our respondents were indeed mothers of infants between 19 and 35 months of age. We addressed this by conducting internal consistency checks to identify and discard implausible responses. Finally, this sample of mothers were well educated and predominantly white; selection bias may explain why infants in our sample were more likely to have consumed any breast milk during the first year of infancy than a national sample.

\section{Conclusion}

Our results highlight that the term "breastfeeding" does not adequately describe the range of contemporary infantfeeding behaviors employed by this sample of U.S. women. Most lactating mothers are expressing breast milk several times every day and most infants are consuming breast milk both at the breast and from a bottle. This is important because we know that the mode of breast milk feeding is associated with infant health outcomes, and that the mode of breast milk feeding is often not addressed on infant-feeding surveys. These results suggest that considerable thought and care must be given to devising infant-feeding questions for use in research, and that revision of current national breastfeeding surveillance questions may be warranted.

\section{Acknowledgment}

This work was funded by the Jean Hankin Nutritional Epidemiology Award from The Academy of Nutrition and Dietetics Foundation.

\section{Supplementary Material}

\section{Supplementary Table S1}

\section{References}

1. Dewey KG, Heinig J, Nommsen-Rivers LA. Differences in morbidity between breast-fed and formula-fed infants. J Pediatr 1995;126:696-702.

2. Ip S, Chung M, Raman G, et al. Breastfeeding and maternal and infant health outcomes in developed countries. Evid Rep Technol Assess (Full Rep) 2007:1-186.

3. Sankar MJ, Sinha B, Chowdhury R, et al. Optimal breastfeeding practices and infant and child mortality: A systematic review and meta-analysis. Acta Paediatr 2015;104:3-13.

4. Disantis KI, Collins BN, Fisher JO, et al. Do infants fed directly from the breast have improved appetite regulation and slower growth during early childhood compared with infants fed from a bottle? Int J Behav Nutr Phys Act 2011;8: 89.

5. Bartok CJ. Babies fed breastmilk by breast versus by bottle: A pilot study evaluating early growth patterns. Breastfeed Med 2011;6:117-124.

6. Li R, Magadia J, Fein SB, et al. Risk of bottle-feeding for rapid weight gain during the first year of life. Arch Pediatr Adolesc Med 2012;166:431-436. 
7. Soto-Ramírez N, Karmaus W, Zhang H, et al. Modes of infant feeding and the occurrence of coughing/wheezing in the first year of life. J Hum Lact 2013;29:71-80.

8. Li R, Scanlon KS, May A, et al. Bottle-feeding practices during early infancy and eating behaviors at 6 years of age. Pediatrics 2014;134 Suppl 1:S70-S77.

9. Boone KM, Geraghty SR, Keim SA. Feeding at the breast and expressed milk feeding: Associations with otitis media and diarrhea in infants. $J$ Pediatr 2016;174:118-125.

10. Klopp A, Vehling L, Becker AB, et al. Modes of infant feeding and the risk of childhood asthma: A Prospective Birth Cohort Study. J Pediatr 2017;190:192-199.e192.

11. Azad MB, Vehling L, Chan D, et al. Infant feeding and weight gain: Separating breast milk from breastfeeding and formula from food. Pediatrics 2018;142.

12. Eidelman AI, Schanler RJ, Johnston M, et al. Breastfeeding and the use of human milk. Pediatrics 2012;129:E827-E841.

13. World Health Organization. The Optimal Duration of Exclusive Breastfeeding: Report of an Expert Consultation. Geneva, Switzerland: World Health Organization, 2001. www.who.int/nutrition/publications/infantfeeding/optimal_ duration_of_exc_bfeeding_report_eng.pdf (accessed August 8, 2017).

14. Bureau of Labor Statistics. Women in the Labor Force: A Databook. Washington DC: Bureau of Labor Statistics 2015, p. 1059. https://www.bls.gov/opub/reports/womensdatabook/archive/women-in-the-labor-force-a-databook-2015 .pdf (accessed August 8, 2017).

15. Geraghty SR, Khoury JC, Kalkwarf HJ. Human milk pumping rates of mothers of singletons and mothers of multiples. J Hum Lact 2005;21:413-420.

16. Shealy KR, Scanion KS, Labiner-Wolfe J, et al. Characteristics of breastfeeding practices among US mothers. Pediatrics 2008;122:S50-S55.

17. Felice JP. A Mixed-Methods Investigation of Pumping Human Milk and Feeding Pumped Milk to Infants. Division of Nutritional Sciences, Ithaca, NY: Cornell University, 2015.

18. Felice JP, Rasmussen KM. Breasts, pumps and bottles, and unanswered questions. Breastfeed Med 2015;10:412-415.

19. O'Sullivan EJ, Geraghty SR, Rasmussen KM. Human milk expression as a sole or ancillary strategy for infant feeding: A qualitative study. Matern Child Nutr 2016;13:e12332.

20. Rasmussen KM, Felice JP, O'Sullivan EJ, et al. The meaning of "breastfeeding" is changing and so must our language about it. Breastfeed Med 2017;12:510-514.
21. Grummer-Strawn LM, Li R. US national surveillance of breastfeeding behavior. J Hum Lact 2000;16:283-290.

22. McGuire S. U.S. Dept. of Health and Human Services. The surgeon general's call to action to support breastfeeding. U.S. Dept. of Health and Human Services, Office of the Surgeon General. 2011. Adv Nutr 2011;2:523-524.

23. Labiner-Wolfe J, Fein SB, Shealy KR, et al. Prevalence of breast milk expression and associated factors. Pediatrics 2008;122 Suppl 2:S63-S68.

24. O’Sullivan EJ, Rasmussen KM. Development, construct validity, and reliability of the Questionnaire on Infant Feeding: A tool for measuring contemporary infant-feeding behaviors. J Acad Nutr Diet 2017;117:1983-1990.e4.

25. Harris PA, Scott KW, Lebo L, et al. ResearchMatch: A national registry to recruit volunteers for clinical research. Acad Med 2012;87:66-73.

26. Keim SA, Boone KM, Oza-Frank R, et al. Pumping milk without ever feeding at the breast in the Moms2Moms study. Breastfeed Med 2017;12:422-429.

27. Mueller NT, Bakacs E, Combellick J, et al. The infant microbiome development: Mom matters. Trends Mol Med 2015;21:109-117.

28. Stewart CJ, Ajami NJ, O'Brien JL, et al. Temporal development of the gut microbiome in early childhood from the TEDDY study. Nature 2018;562:583-588.

29. Labiner-Wolfe J, Fein SB. How US mothers store and handle their expressed breast milk. J Hum Lact 2013;29: 54-58.

30. Lawrence RA. Storage of human milk and the influence of procedures on immunological components of human milk. Acta Paediatr Suppl 1999;88:14-18.

31. O'Sullivan EJ, Geraghty SR, Rasmussen KM. Informal human milk sharing: A qualitative exploration of the attitudes and experiences of mothers. J Hum Lact 2016;32: 416-424.

Address correspondence to: Elizabeth J. O'Sullivan, PhD School of Biological and Health Sciences Technological University Dublin Room 2029A, Kevin Street Dublin 8 Ireland

E-mail: liz.osullivan@dit.ie 